\title{
Endothelial progenitor dysfunction in the pathogenesis of diabetic retinopathy: treatment concept to correct diabetes-associated deficits
}

\author{
Sergio Li Calzi • Matthew B. Neu $\cdot$ Lynn C. Shaw \\ Maria B. Grant
}

Received: 19 January 2010 / Accepted: 10 February 2010 /Published online: 13 April 2010

(C) European Association for Predictive, Preventive and Personalised Medicine 2010

\begin{abstract}
Progressive obliteration of the retinal microvessels is a characteristic of diabetic retinopathy and the resultant retinal ischemia can lead to sight-threatening macular edema, macular ischemia and ultimately preretinal neovascularization. Bone marrow derived endothelial progenitor cells (EPCs) play a critical role in vascular maintenance and repair. There is still great debate about the most appropriate markers that define an EPC. EPCs can be isolated using cell sorting by surface phenotype selection or in vitro cell culture. For freshly isolated cells, EPC cell sorting is heavily dependent on the surface markers used; EPCs can also be isolated by in vitro propagation of heterogeneous mixtures of cells in culture using adhesion to specific substrates and cell growth characteristics. in vitro isolation enables consistent reproducibility and using this approach at least two distinct types of EPCs with different angiogenic properties have been identified from adult peripheral and umbilical cord blood; early EPCs (eEPCs) and late outgrowth endothelial progenitor cells (OECs). Emerging studies demonstrate the potential of these cells in revascularization of ischemic/injured retina in animal models of retinal disease. Since ischemic retinopathies are leading causes of blindness, they are a potential disease target for EPC-based therapy. In this chapter, we summarize the current knowledge about EPCs and discuss
\end{abstract}

\footnotetext{
S. Li Calzi • M. B. Neu • L. C. Shaw $\cdot$ M. B. Grant

Department of Pharmacology and Therapeutics,

University of Florida,

Gainesville, FL, USA

\section{B. Grant ( $\square)$}

Department of Pharmacology and Therapeutics,

College of Medicine, University of Florida,

Box 100267, ARB, 1600 SW Archer Road,

Gainesville, FL 32610, USA

e-mail: grantma@ufl.edu
}

the possibility of cellular therapy for treatment of diabetic macular ischemia and the vasodegenerative phase of diabetic retinopathy. We also report current pharmacological options that can be utilized to correct diabetes associated defects in EPCs so as to enhance the therapeutic utility of these cells.

Keywords Angiogenesis · Endothelial progenitor cells . Adult stem cells · Diabetic retinopathy · Ischemia .

Targeted treatment

Diabetic retinopathy, the leading cause of visual impairment in the western world [1], will occur in the majority of type 1 diabetic patients and about $20-30 \%$ will advance to the blinding stage of the disease. Greater than $60 \%$ of patients with type 2 diabetes will develop retinopathy. With the global epidemic of obesity and subsequently of type 2 diabetes, this predicament is likely to worsen. Over 360 million people are projected to suffer from diabetes and its complications by 2030 .

Hyperglycemia damages retinal microvasculature, which results in increased permeability, blood and serum leakage to the extra vascular space, and progressive decline in retinal blood flow; as well as closure of the retinal microvasculature leading to diabetic retinopathy. Diabetic retinopathy is thought to be largely a result of diabetesinduced retinal microvascular dysfunction and is characterized by capillary leakage (loss of the functional integrity of the blood retinal barrier) or capillary closure resulting in ischemia (the formation of acellular capillaries, with loss of blood supply to the neural retina). Capillary leakage causes diabetic macular edema (DME), the principal cause of vision loss in diabetes. Capillary closure in the retina leads to diabetic macular ischemia (DMI) and causes loss of reading vision. Bilateral DMI causes legal blindness and 
unfortunately there is no therapy for DMI. Moreover, patients commonly have mixed DME and DMI. In addition, the level of damage to the microvasculature is impacted by the duration of diabetes, the degree of blood sugar and hypertension control, and yet to be determined patient-specific differences in the ability to repair the damaged endothelium.

Strict metabolic and blood pressure control can lower the risk of developing retinopathy and reducing disease progression [1]. Newer therapies targeted at treating either DMI or PDR include corticosteroids and anti-VEGF antibodies. These approaches represent promising alternatives to control retinopathy progression. Laser therapy, the standard of care for DME, can be destructive to various neurovascular layers of the retina and choroid, but results in modest preservation of visual acuity [2, 3]. However, actual improvement in visual acuity is uncommon. Laser is less effective in the presence of diffuse or chronic DME and in the presence of "mixed" DME and capillary closure [3]. When retinopathy progresses to the late stages, chronic hypoxia/nonperfusion leads to compensatory neovascularization which occurs in an aberrant manner mostly on the surface of the retina. For this stage, proliferative diabetic retinopathy, laser treatment is the most cost effective approach. However, anti VEGF approaches similar to those used for choroidal neovascularization show considerable promise [4].

Endothelial progenitor cells (EPCs) are now recognized as a key cell responsible for healthy maintenance of the vasculature, including the retina. EPCs are believed to be derived from hematopoietic stem cells (HSCs, Fig. 1) or alternatively the endothelium itself [6]. In the last decade, it has been recognized that EPCs are recruited to sites requiring repair where these cells contribute to the viability of the vasculature [7]. Because EPCs home to sites of damage and promote vascular integrity, they not only mediate repair of injured tissue but lead to reperfusion of ischemic regions within a tissue [8]. Following the discovery of EPCs by Asahara and coworkers, EPC repair has been observed in a wide array of processes including myocardial ischemia/infarction, limb ischemia, wound healing, atherosclerosis, endogenous endothelial repair, and tumor neovascularization in mice and humans [7, 9]. This repair occurs as a series of carefully orchestrated steps: 1) EPC mobilization from bone marrow, 2) EPC circulation to remote sites of vascular injury, 3) extravasation of EPCs from the circulation into the area of injury and 4) finally the assimilation with the local endothelium or paracrine support to the local endothelium (Fig. 2). EPCs comprise $0.02 \%$ of the total bone marrow, compared to $4 \%$ by $\mathrm{GR} 1^{+}$myeloid cells for example, and their incorporation into vessels varies dramatically depending on the vascular bed and the type of injury. An engraftment efficiency of up to $95 \%$ is observed in some vascular beds [11]. Specifically, Minami et al. have shown that circulating EPCs engraft luminally into $15 \%$ to
$29 \%$ of vessels in the transplanted human heart [12]. Bone marrow derived endothelial cells have also been shown to give rise to up to $16 \%$ of the neovasculature in spontaneous tumors grown in transgenic mice [13] and they also contribute to human tumor vessels [14].

Our group has observed very high numbers of bone marrow derived cells contributing to both repair and pathological neovascularization in the eye $[15,16]$. We interpreted this high percentage to be secondary to the highly quiescent nature of the resident retinal vasculature (typical retinal endothelial cells turnover occurs every 4 years), thus facilitating the contribution of circulating EPCs to the newly forming vessel.

\section{Characterization of EPCs}

Characterization of the various EPC subpopulations is an area of heated debate but there exist two main approaches to define and/or isolate cells with endothelial characteristics and regenerative capacity: culture selection from mononuclear cells (either BM- or PB-derived) or the use of a set of antibodies to various "identifying" markers of these cells.

\section{Identification of endothelial precursors based on culture}

Asahara and colleagues first characterized the endothelial precursors in 1997 as a subset of CD34 ${ }^{+}$hematopoietic progenitor cells [7]. They reported that peripheral blood mononuclear cells (PB-MNCs) enriched for $\mathrm{CD}^{+} 4^{+}$cells could differentiate into endothelial-like cells following culture on fibronectin in the presence of growth factors. After 7 days in culture the fraction of cells co-expressing CD34 and VEGFR-2 increased. These cells also expressed other endothelial markers such as CD31 (platelet endothelial cell adhesion molecule-1, PECAM-1), tyrosine kinase with immunoglobulin-like and EGF-like domains 2 (Tie-2) and eNOS, incorporated acetylated low-density lipoprotein (acLDL), bound Ulex (UEA-1) lectin and formed tube-like structures in vitro, supporting the contention that they possess the ability to differentiate into endothelial cells. These findings were corroborated by Shi et al. [17]. Currently, culture selection involves the growth of PBMNCs in selective medium and on either fibronectin- or collagen-coated dishes [17]. The medium typically contains a cocktail of endothelial growth factors, such as VEGF, FGF2, IGF-1, PDGF-BB, as well as ascorbic acid and hydrocortisone. The medium is changed regularly (usually every 24 $28 \mathrm{~h}$ ). Culture-selected cells can be classified into two distinct phenotypes as shown in Fig. 3 [18].

eEPCs, which are the cells originally identified by Asahara, have been most studied to date. eEPCs are those 
Fig. 1 Adult stem cells of the bone marrow. The bone marrow hosts at least two known types of adult stem cells, the mesenchymal stem cells (MSC) and the hematopoietic stem cells (HSC); the most prominent adult stem cell in the bone marrow. The HSC can give rise to the hematopoietic progenitor cells (HPC) which in turn give rise to the lymphoid progenitor cell, the myeloid progenitor cells, and likely the EPC. The precise origin of the EPC is under debate as this cell may directly arise from the HSC or from the HPC. The bone marrow microenvironment is composed of bone marrow stromal cells (which are the source of SDF-1), adipocytes, and cells of the bone matrix, osteoblasts and osteoclasts. The vessels within the bone marrow, composed of pericytes and endothelium, function to provide a barrier between the hematopoietic compartment and the circulatory system. Figure adapted from Domen, et al. [5]

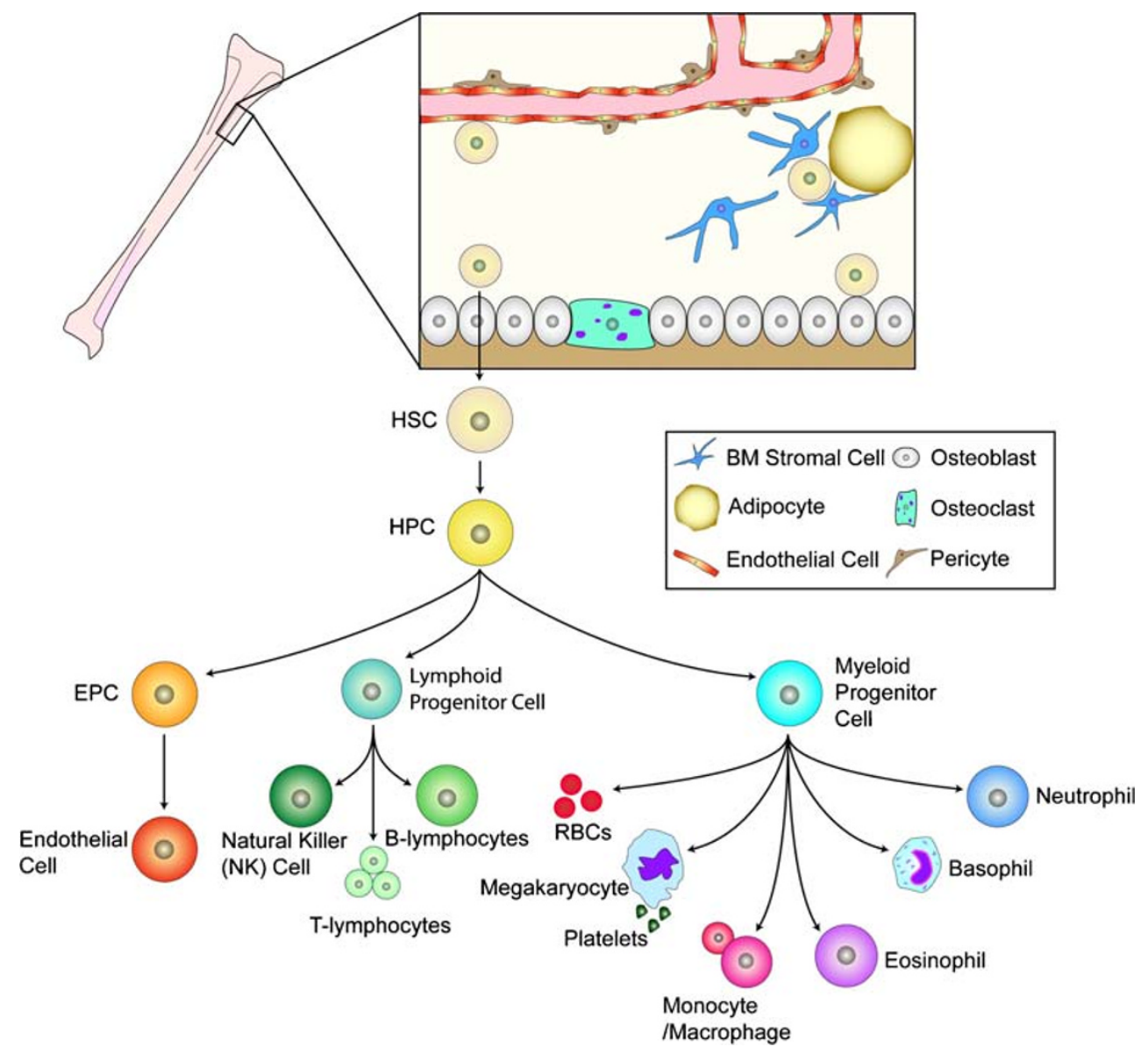

mainly derived from monocytes, do not proliferate and begin to gradually die after a few weeks in culture $[18,19]$. In contrast, OECs usually begin growing $>2$ weeks after isolation, eventually proliferate very rapidly, resemble microvascular ECs (with a cobblestone morphology), and seem to be expandable indefinitely (Fig. 4) [20, 21]. The distinction between these two cell types is reinforced by their expression of different markers. OECs do not express CD1a or CD14 and have a low expression of CD45, the pan-leukocyte marker [22]. The precise origin of the $\mathrm{OEC}$ is still in question yet, Yoder's group believes that the endothelium is the source of this progenitor. The OEC represents one cell in a million MNC found in the circulation and thus can only be "identified" once it has grown out in culture [23].

Most early studies of cell therapy in the heart and limbs employed eEPCs; thus, there is abundant evidence that these transplanted cells can enhance revascularization [24], although there is much debate about the mechanism of these effects. In contrast, OECs have been minimally studied in vivo [25]. Still their higher proliferative potential may be important when a large supply of regenerative cells is required. Thus, OECs may have great therapeutic utility as a cellular therapy [8]. It is our belief that both the CD34 ${ }^{+}$ cell and the OEC population are transiently lost in nonproliferative diabetic retinopathy (NPDR) but, when this population reappears, it does so as a more aggressive and proliferative phenotype and upon reappearance, triggers the angiogenic switch in proliferative diabetic retinopathy (PDR). The eEPC population never disappears entirely but rather shifts in its level of activity, sometimes being more inflammatory than other times; thus its phenotype also changes with the severity of retinopathy, being more inflammatory in PDR and less in NPDR. Moreover, it has been shown by Yoon et al. that early and late outgrowth EPCs can act together to stimulate vascular repair [25].

\section{Identification of EPCs based on FACS or magnetic bead selection}

In contrast to differential culture, many groups including ours, have characterized endothelial precursors using a panel of immunological and non-immunological markers in freshly isolated cells and used these sorted cells directly for either in vitro or in vivo studies. This is the approach commonly used for the isolation of cells (from a patient's own $\mathrm{BM}$ or $\mathrm{PB}$ ) for therapeutic use. The original combination of CD34 and VEGFR-2 remains the most common, but several other markers have been used to refine the identification of this therapeutic cell type. Some 


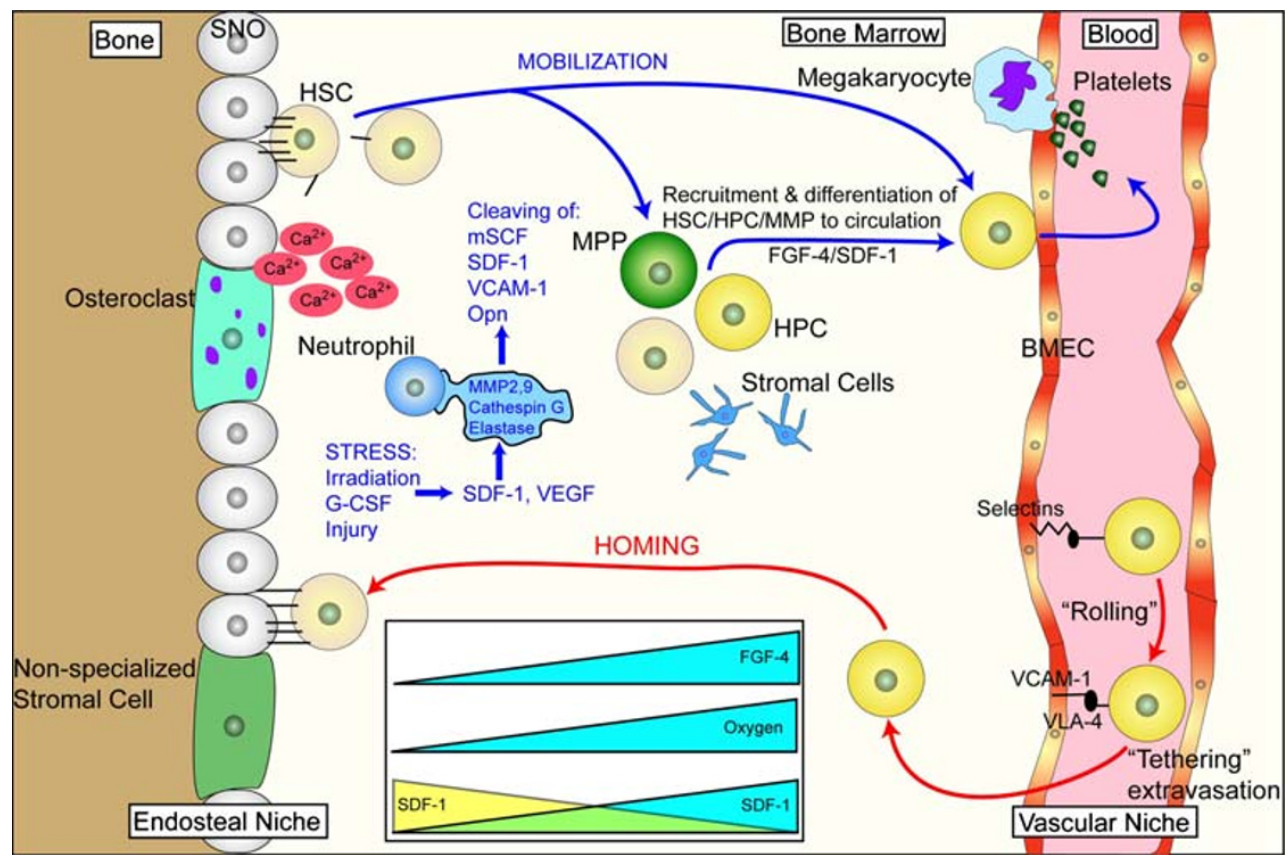

Fig. 2 Mobilization and homing are two closely related processes. Mobilization involves the exodus of HSC/HPC from the bone marrow into the circulation while homing is the "opposite" of this event. HSC mobilize from the endosteal niche, move to the vascular niche, and ultimately into the circulation. This normally occurs when stress induces changes of SDF-1 levels in the bone marrow. The mechanism of stress-induced mobilization as occurs following irradiation or G-CSF-induced mobilization is not fully known, but is, in part, accomplished by the upregulation of proteases such as MMP-2, MMP9 , cathepsin- $\mathrm{G}$ and elastase. These proteases cleave niche retention signals like membrane-bound stem cell factor (mSCF), SDF-1, VCAM-1 and osteopontin (Opn). Gradients of fibroblast growth factor 4 (FGF-4) also regulate mobilization. For homing events, key steps are needed. Upon reaching the bone marrow vasculature, SDF-1-

have described CD133 (prominin) as an additional marker [26] particularly to identify immature EPCs.

BM-derived $\mathrm{CD} 14^{+}$monocytes also demonstrate potential to differentiate into endothelial cells [18]. Interestingly, although several independent groups have shown a clear development of an endothelial phenotype after selective culture, many also found that the expression of monocytic antigens persisted $[18,27]$. Several additional studies confirmed the overlap between EC and monocyte phenotypes, suggesting that using traditional EC markers such as acLDL uptake, Ulex binding, CD31, CD105 (endoglin), CD144 (vascular endothelial cadherin), VEGFR-2, CD34 and Tie-2 may not be enough to distinguish between ECs and monocytes, and thus may not specifically identify EPCs [28-30]. Similarly, Harraz et al. showed that cultured CD $34^{-} \mathrm{CD} 14^{+}$PB-MNCs express Tie-2, VEGFR-2, CD144, von Willebrand factor (vWF), CD146, CD105 and eNOS [27]. Interestingly, another report suggested that monocytes $\left(\mathrm{CD} 14^{+}\right)$, which express low levels of CD34 (undetectable with conventional techniques), may in fact contain the true progenitor cell population, with stimulated circulating HSC/HPC express integrins such as very late antigen 4 (VLA-4) and hyaluronan binding-cellular adhesion molecule (CD44). These integrins, in turn, interact with vascular cell adhesion molecule 1 (VCAM-1), intercellular adhesion molecule 1 (ICAM-1), E-and P-selectins expressed on bone marrow endothelial cells which slows down the circulating HSC/HSP in a process known as "rolling." Following rolling, firm adhesion and subsequent endothelia transmigration into the hematopoietic compartment is mainly accomplished by VLA-4 interactions. Once extravasated the cells, the cells migrate along extravascular hematopoietic cords toward specific niches through as SDF-1 gradient or receding oxygen gradient originating from the supporting osteoblastic or endothelia niches. BMEC: Bone marrow microvascular endothelial cell. Figure adapted from Wilson and Trumpp [10]

the greatest regenerative capacity [31]. Considering the uncertainty as to the most reliable method to identify circulating EPCs, several studies have employed CD34/VEGFR-2 or CD34/ CD133 double positivity to quantify circulating EPCs and to correlate their concentration to clinical conditions $[32,33]$. This is the strategy that we have used for most of our studies.

The failure to reliably characterize endothelial progenitors has generated some skepticism and confusion within the field of regenerative medicine. However, a study by Loomans et al. [34] and an excellent review by Schatteman et al. [8] have suggested that despite phenotypic overlap between various BM-derived or circulating cell types, the endothelial phenotype can best be characterized by three features: eNOS expression, integration into tube-like structures formed by human umbilical vein ECs (HUVECs), and stimulation of tube formation by HUVECs. It is suggested that these criteria might be the best in vitro method of judging the endothelial phenotype, regardless of the presence or absence of particular cell surface antigens. This simplified interpretation is important, as it acknowledges 


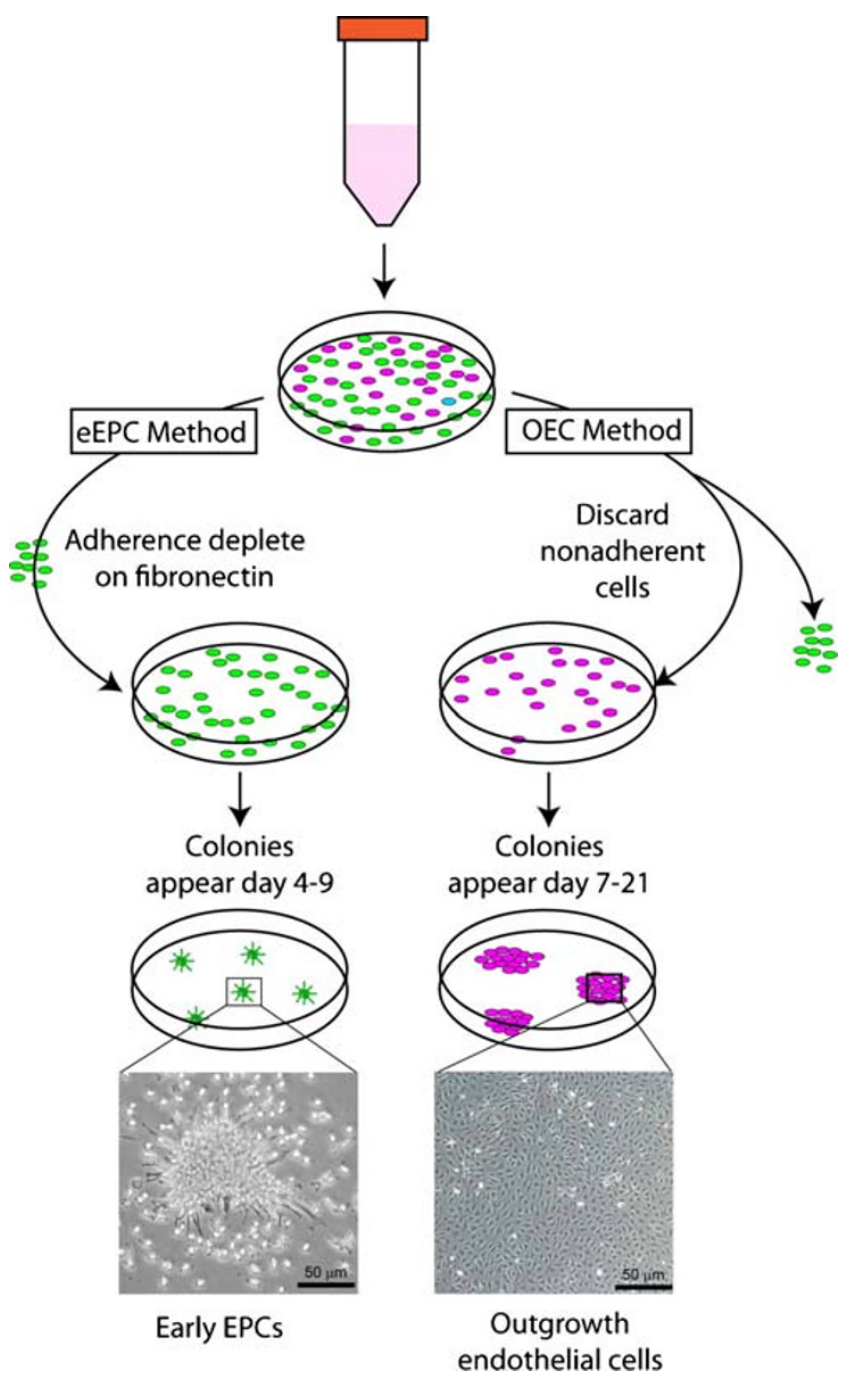

Fig. 3 Common methods of precursor isolation. Culture of eEPCs includes a 5-day process wherein non-adherent MNCs give rise to the EPC colony. OECs are derived from adherent MNCs cultured on collagen for 21 days in endothelial growth conditions and demonstrate typical cobblestone morphology

the limitation of surface markers and affirms the importance of the identification of EPCs according to their potential to acquire functional properties of ECs.

\section{The importance of progenitor characterization to the pathogenesis of DR}

Our working hypothesis is that populations such as freshly isolated $\mathrm{CD}_{14}{ }^{+}$cells and eEPCs are responsible for "provisional repair," that is, transient repair preparing the environment for a more durable repair, which we believe is the function of the $\mathrm{CD} 34^{+}$cell and the OECs. In healthy retina both populations are participating in a temporal manner with $\mathrm{CD} 14^{+}$cells and eEPCs homing in first, attracting the $\mathrm{CD} 34^{+}$cells and OECs later. In NPDR, eEPCs (and $\mathrm{CD} 14^{+}$cells) have reduced function as they cannot recruit $\mathrm{OEC}$ (and $\mathrm{CD} 34^{+}$cells) into the retina to repair the acellular capillaries, while in PDR the eEPCs take on a proinflammatory phenotype and recruit too many OECs leading to pathological neovascularization. This distinction may be critically important to the derivation of cellular therapies. It is our contention that for durable repair and sustained correction of retinal ischemia the use of cells that are expanded in vitro (eEPCs and OECs) may be better than freshly isolated cells. Moreover, this extended ex vivo period allows more time for correction of diabetes-induced dysfunction, which is described below. How does the cell type that we have spent a decade characterizing in DR, that is the CD $34^{+}$VEGFR-2 $2^{+} \mathrm{EPC}$, fit into all this? The origin of the OEC is from a $\mathrm{CD} 34^{+}$ VEGFR- $2^{+}$population found in the circulation $[6,25,35]$.

\section{Diabetic EPCs are dysfunctional}

In diabetes BM-derived progenitors are dysfunctional, producing fewer endothelial cells with reduced proliferative and migratory potential [36]. Enhanced oxidative stress in diabetes contributes to progenitor dysfunction [37]. Accumulation of ROS increases cellular/replicative senescence in these progenitors as does increased angiotensin II, oxidized low-density lipoprotein (ox-LDL) and homocysteine. EPCs of diabetic origin show a reduced ability to integrate into EC tubes in vitro compared to EPCs of non-diabetic origin [3840]. Vascularization is depressed when EPCs from STZ treated mice are injected into normal mice [41]. Recently, we showed that activation of the HDL receptor is protective to EPCs by increasing eNOS [42], whereas activation of ox-LDL receptor down-regulates eNOS, supporting a key role for NO in the function of progenitors [43].

Our group and others have evidence that the development of acellular capillaries may be due to failed attempts at repair of injured capillaries and persistence of ischemia. For the last 10 years, our group has focused on understanding the basic mechanism responsible for the diabetes-associated defect in EPC function. Correcting this defect may allow the use of a diabetic patient's own EPCs for repair of their injured retinal and systemic vasculature. Specifically in the retina, correction of this dysfunction could treat early and intermediate stages of vasodegeneration to enhance vessel repair, reverse ischemia, and prevent progression to the late stages of DR (Fig. 5). However before EPCs can be used therapeutically in DR to reendothelialize acellular capillaries and eliminate retinal ischemia, several key questions must be answered. What triggers this phenotypic change in diabetic cells taking them from reparative to deleterious? What is the best reparative BMDC population? Are some subpopulations more resistant to the injurious effects of diabetes? Should the BM be a target for DR therapy? 
Fig. 4 Morphology of Early and Late Outgrowth EPCs. (A) Typical colony of early EPCs which develop into spindle shaped cells by day 7 (B). Early EPCs do not proliferate readily, which leads to the typical subconfluent appearance. In contrast, late outgrowth ECs (C) show rapid growth as indicated by the dividing cell (black arrow) and display the typical endothelial cobblestone morphology and proliferate abundantly (D)
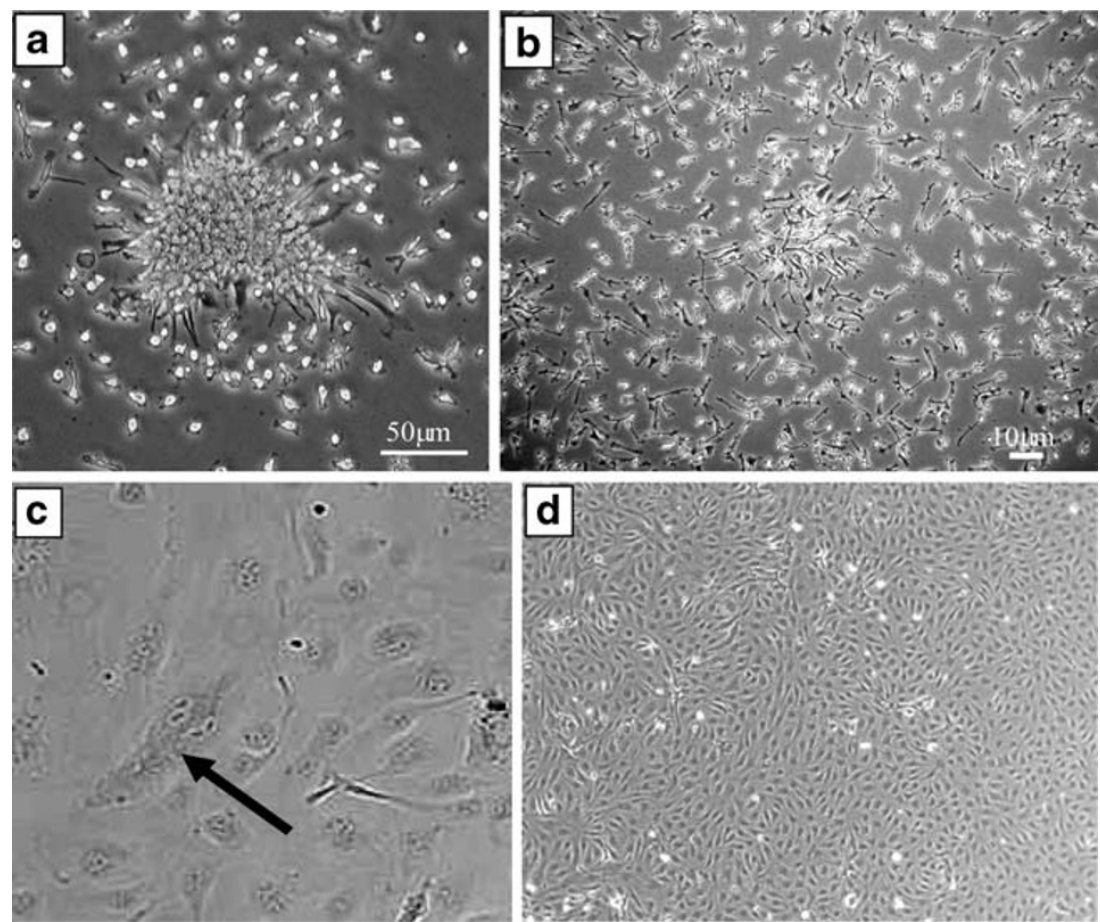

\section{Nitric oxide (NO) in the pathogenesis of DR}

NO generation arises from the guanidino group of Larginine and is a NADPH-dependent reaction catalyzed by a family of NOS. Three distinct isoforms of NOS, consisting of endothelial NOS (eNOS), neuronal NOS (nNOS), and inducible NOS (iNOS) are similar in structure and function, utilizing L-arginine, oxygen and NADPH as substrates, and requiring FAD, FMN, calmodulin, and tetrahydrobiopterin as co-factors. The catalytic mechanism of NOS involves flavin-mediated electron transport from $\mathrm{NADPH}$ to the terminal heme, where oxygen is bound and incorporated into NO and citrulline [44]. Maintaining an adequate cellular supply of L-arginine is critical for normal

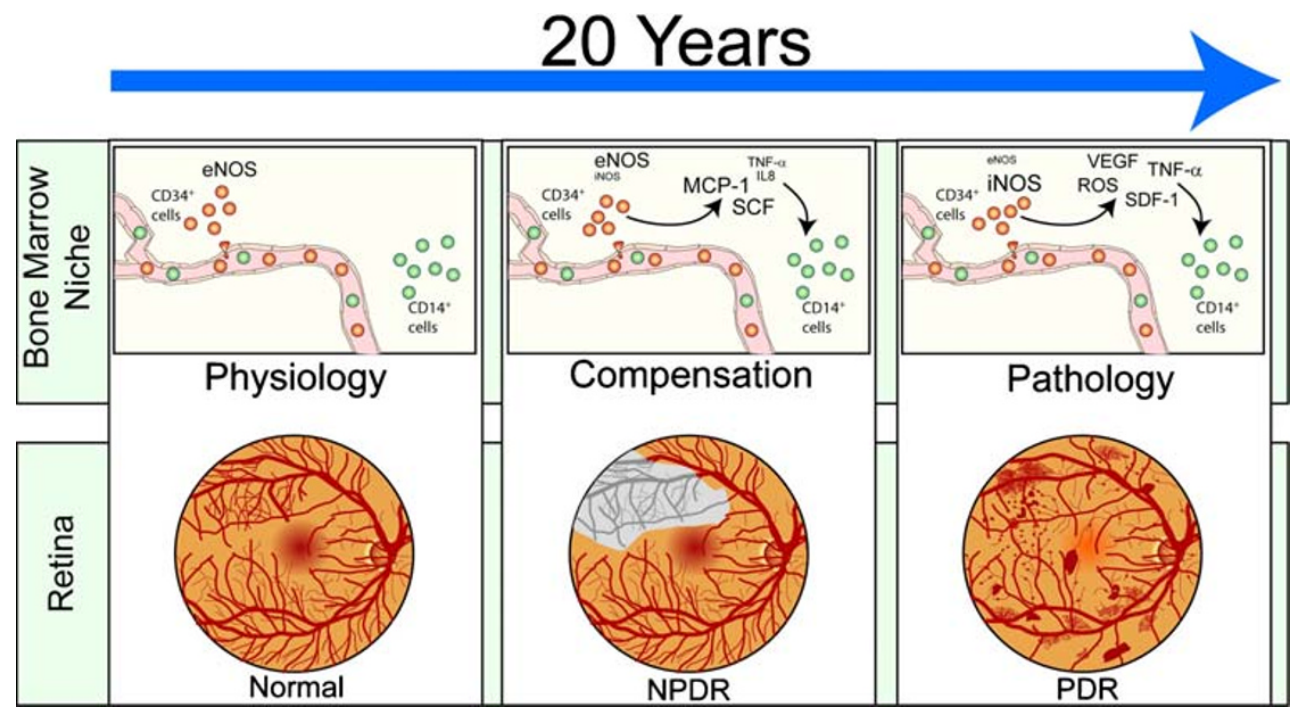

Fig. 5 Schematic of the hypothetic diabetic retinopathy progress. In physiological conditions, CD $34^{+}$EPCs contribute to routine blood vessel maintenance through eNOS activation and NO-mediated stimulation of $\mathrm{CD} 14^{+}$EPCs. In diabetes, initially, cytokines like stem cell factor (SCF), monocyte chemoattractant protein-1 (MCP-1), interleukin-8 (IL-8), and tumor necrosis factor alpha (TNF- $\alpha$ ) released by dysfunctional $\mathrm{CD} 34^{+}$EPCs initiate $\mathrm{CD} 14^{+}$EPC-mediated aberrant vascular repair resulting in retinal ischemia. This phase is referred to as non proliferative diabetic retinopathy (NPDR). The vasodegenerative phase of diabetic retinopathy associated with reduced reparative function of EPCs evolves in the proliferative diabetic retinopathy (PDR). This phase is characterized by pathological neovascularization seen in the diabetic retina 
vascular function. Deficiencies in L-arginine supply have been strongly implicated in vascular diseases, including diabetes [45]. If the supply of L-arginine or any cofactor does not meet the needs of active NOS, NOS becomes "uncoupled" and uses molecular oxygen as a substrate to form $\mathrm{O}^{2-}$ instead of NO. An imbalance between L-arginine availability and NOS activity can occur when cellular transport of L-arginine is inhibited [46] or when there is reduced recycling of L-citrulline back to L-arginine, or when an elevated catabolism of L-arginine by arginase exists [47, 48].

We demonstrated in a spontaneous rat model of type 2 diabetes that eNOS was decreased while NADH oxidase, a major source of superoxide in the vascular endothelium, iNOS, and $\mathrm{ONOO}^{-}$were all increased in the retinal vasculature [49]. The shift in redox state in diabetes with increased ROS causes increased interaction of $\mathrm{NO}$ with $\mathrm{O}^{2-}$, resulting in loss of bioavailable $\mathrm{NO}$ and formation of $\mathrm{ONOO}^{-}$. The reduced $\mathrm{NO}$ and elevated $\mathrm{ONOO}^{-}$can lead to microvascular dysfunction in diabetes [50-52]. $\mathrm{ONOO}^{-}$is a potent oxidant that can attack many types of biological molecules; a high level of $\mathrm{ONOO}^{-}$initiates lipid peroxidation, hydroperoxides, nitration of amino acids such as tyrosine, oxidation of antioxidants such as ascorbic acid and $\alpha$-tocopherol, and direct DNA damage. The increased oxidative stress associated with diabetes can limit tetrahydrobiopterin availability. Moreover, $\mathrm{ONOO}^{-}$formation affects tetrahydrobiopterin interaction with NOS [53], leading to this "switch" or uncoupling of NOS from producing NO to producing $\mathrm{O}^{2-}$. Advanced glycation end products (AGEs) seen in the diabetic individuals can also directly react with $\mathrm{NO}$, diminishing $\mathrm{NO}$ bioavailability both in vitro and in vivo [54].

In type 1 diabetes, uncoupled eNOS was found to be the major source of ROS generation and, when blocked, there was reduced retinal leukostasis, blood retinal breakdown and reduced retinopathy [55]. Whereas nNOS is highly expressed in the retina, its role in DR is still being determined. Interestingly, nNOS knock-out mice still develop retinal leukostasis and blood retinal barrier breakdown suggesting that iNOS or eNOS may have a more central role in these particular aspects of DR. In a model of diabetic ketoacidosis, in which acetone is administered to a mouse, tissue damage is mediated by free radical generation via iNOS overexpression [56]. Diabetes-induced vascular dysfunction in rats was prevented by administration of a specific inhibitor of iNOS, 1400W [57, 58].

\section{Is reduced bioavailable NO responsible for the endothelial progenitor dysfunction observed in DR?}

NO-mediated signaling pathways are essential for EPC mobilization from the BM [59-61]. NO activates MMP-9, releasing soluble Kit ligand, which shifts EPCs and hematopoietic stem cells (HSCs) from a quiescent to a proliferative niche and stimulates rapid cell mobilization to the PB $[60,62]$. NO regulates migration of EPCs into ischemic sites [59, 63-65] and their survival [66]. We and others have shown that diabetic EPCs have decreased eNOS activity; more importantly that exogenous $\mathrm{NO}$ can correct the migratory defect in these cells (Fig. 6) [67, 68]. The impaired in vivo re-endothelialization capacity of human diabetic EPCs was restored by small interfering RNA silencing of NAD(P)H oxidase subunit p47(phox) [64]. Oxidative stress impairs in vivo reendothelialization capacity of endothelial progenitor cells [69]. We show in the preliminary data that pretreatment of diabetic CD34 ${ }^{+}$VEGFR-2 ${ }^{+}$EPCs with apocynin or gp91ds-tat decreased superoxide production and increased NO availability. Pretreatment with apocynin or gp91ds-tat reversed the impaired migration of diabetic EPCs in response to SDF-1 and VEGF in vitro and enhanced their integration into ischemic retinal vasculature in vivo [70]. Propofol, a peroxynitrite scavenger, inhibits NF-kB activation, increases NO production and protects EPCs from apoptosis

\section{Non-diabetic Environment}

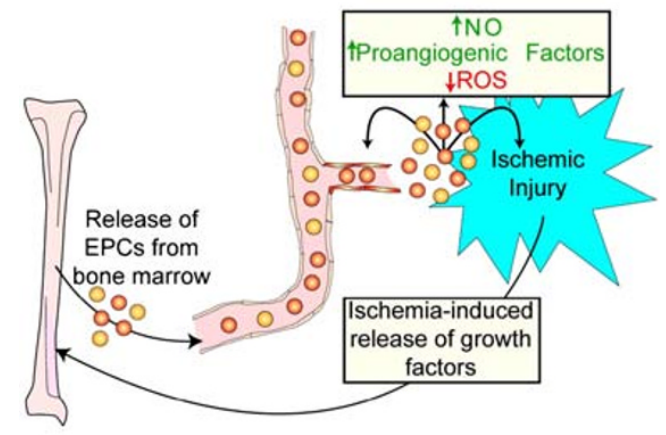

Diabetic Environment

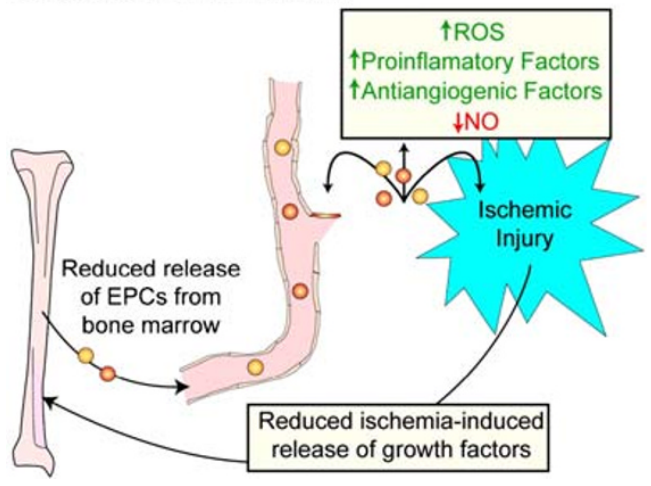

Fig. 6 Release of EPCs is reduced in a diabetic environment. In a non-diabetic environment ischemic injury results in the release of growth factors at the site of injury which stimulate the release of EPCs from bone marrow. EPCs then migrate to the site of injury and initiate blood vessel repair (angiogenesis). In a diabetic environment ROS, proinflamatory and antiangiogenic factors are increased above nondiabetic levels while NO is reduced. This results in a blunted response to ischemic injury and marginal repair at the site of injury 
[38, 71, 72]. High glucose enhances EPC senescence, impairs migration and tube formation. These effects can be ameliorated by co-incubation with the NO donor sodium nitroprusside and worsened by eNOS inhibition [73]. Diabetic EPC dysfunction was improved by the eNOS activator AVE 9488 and with PPAR $\gamma$-agonists $[74,75]$. Specifically, these agonists promote differentiation, increase EPC number and migratory activity, and reduce EPC apoptotic rate [76]. Decreased NO can be due to increased oxidative degradation as well as reduced synthesis. ADMA, an analogue of the amino acid L-arginine, inhibits the formation of $\mathrm{NO}$ and augments vascular oxidative stress, partly via eNOS uncoupling, resulting in higher superoxide radical generation. ADMA levels are increased in diabetes [76] and ADMA represses EPC proliferation, differentiation, and function, in a concentration-dependent manner [77]. The enzyme dimethylarginine dimethylaminohydrolase (DDAH) inactivates ADMA and regulates NO production [78]. Overexpression of DDAH in vitro and in vivo increased NO production [79].

\section{BM microenvironment is dysfunctional in diabetes}

The BM stem cell niche is a specialized microenvironment that nurtures and regulates the stem cell pool. We showed that diabetic BM has large amounts of fat compared to BM from healthy controls [80]. Adipocyte-rich marrow harbors a decreased number of progenitors and relatively quiescent stem cells. Mice that are genetically deficient in adipogenesis show accelerated hematopoietic recovery after BM ablation, a phenomenon that can be reproduced pharmacologically in wild-type mice through PPAR- $\gamma$ inhibition [81]. These results suggest a novel therapeutic approach to enhance hematopoietic engraftment after marrow or cord blood transplantation, or to ameliorate aplasia in genetic BM failure syndromes. Furthermore, this is a mechanism for the myelosuppression observed in patients treated with the PPAR- $\gamma$ agonist rosiglitazone [8284], a diabetes drug known to increase marrow adiposity [85].

$\mathrm{BM}$ adipocytes have a primarily suppressive effect on hematopoiesis within the BM microenvironment. BM adipocytes are less supportive of hematopoiesis in vitro than their undifferentiated stromal or pre-adipocytic counterparts, in part due to reduced production of growth factors such as granulocyte-macrophage colony-stimulating factor (GM$\mathrm{CSF}$ ) and granulocyte colony-stimulating factor (G-CSF) [86, 87]. Moreover, adipose tissue secretes neuropillin-1 [88], lipocalin [89, 90], adiponectin [91] and TNF- $\alpha$ [92], each of which can impair hematopoietic proliferation. Of note, TNF- $\alpha$ and adiponectin inhibit progenitor activity $[25$, $92,93]$ suggesting that adipocytes prevent hematopoietic progenitor expansion. Adipocytes and osteoblasts originate from mesenchymal stem cells within the BM, where both compartments hold a reciprocal relationship [93]. Balancing the supportive role of the osteoblast in the HSC niche, our and others' data implicate adipocytes as negative regulators of hematopoiesis and that the diabetic fatty marrow has a deleterious effect on EPC function.

Thus, based on these observations, we conclude that both freshly isolated and expanded EPCs can potentially be used for restoration of injured retinal vasculature and that this ultimately will lead to correction of retinal ischemia by restoring proper blood flow to the retina. Whether $\mathrm{CD} 34^{+}$ cells, angiogenic monocytes, such as $\mathrm{CD} 14^{+}$cells, eEPCs or OECs represent the cell population with the greatest therapeutic utility is currently unknown and if there are unique characteristics of the retinal vasculature that make one of these populations better suited for repair is also unknown. Only future studies will provide the needed information of determining the most effective cell therapy for diabetes induced vasodegenerative disease of the retina. The $\mathrm{CD} 14^{+}$cells and the eEPC, we believe, are responsible for "provisional repair," that is transient repair preparing the environment for more "durable repair," which is the function of the $\mathrm{CD}_{3} 4^{+}$cells and the OECs. In healthy retina, both populations participate in an ordered, temporal sequence with for example EPCs homing in first, attracting the OECs later. However, in NPDR, eEPCs have reduced function and cannot recruit OECs leading to ineffective repair of damaged capillaries and the development of acellular capillaries. Further complicating this situation, we believe that OECs may be markedly reduced in numbers in NPDR and may even be "transiently lost" from the circulation; thus are not available for repair of acellular capillaries either. Perhaps in PDR, OECs reappear as a more aggressive and proliferative phenotype which triggers the "angiogenic" switch and the onset of PDR or the eEPC population is more aggressive too. Likely there exists a shift in the level of activity of eEPCs as diabetic retinopathy progresses, being more inflammatory in PDR (and less in NPDR). In both populations, dysregulation of NOS is central to these phenotypic transitions, which are further influenced by the changing BM microenvironment associated with diabetes. Ex vivo correction of the diabetes-induced defects in these cells, or systemic modulation of the BM to correct the dysfunction of these cells will reduce the development of retinopathy. We showed that healthy but not diabetic $\mathrm{CD} 34^{+}$cells attached and assimilated into the retinal vasculature [15]. These studies show the potential of EPC therapy for ischemic retinopathies but they also highlight the need for a more thorough characterization of EPC subsets so that the precise fate and utility of delivered cells can be determined without the potential to evoke unwanted responses. This is especially important in the context of a complex milieu such as diabetes which is known to alter EPC phenotype. For example, Sca- $1^{+}$bone marrow-derived EPCs transplanted into diabetic mice convert to a pro- 
inflammatory and anti-angiogenic phenotype and exacerbate limb ischemia [94]. Therefore, transplanting the wrong cell type into the diabetic retina could enhance differentiation could potentially promote switch to proliferative retinopathy

\section{EPC in ocular angiogenesis}

Retinopathy is the most common diabetic complication with almost all diabetic patients developing background retinopathy [95]. Both type 1 and type 2 diabetes is associated with widespread EPC dysfunction [96]. Several studies have shown that circulating EPC number is reduced in patients with NPDR [97] but increased in patients with PDR [98]. These observations were confirmed by Brunner et al. who conducted a case-control study that compared 90 patients with type 1 diabetes with and without retinopathy. They also demonstrated that in type 1 patients with retinopathy, EPCs underwent stage-related regulation. In NPDR, a reduction of EPCs was observed, while in proliferative retinopathy, a dramatic increase of mature EPCs was observed [99]. These findings are consistent with the hypothesis that the vasodegenerative phase of diabetic retinopathy is associated with reduced reparative function of EPCs and that in PDR these cells may be responsible for the pathological neovascularization seen in the diabetic retina.

Astrocytes, as mentioned earlier, are known to play a pivotal role in the normal developmental retinal vascularization. Otani et al. showed that intravitreally injected Lin-BM cells selectively target retinal astrocytes, cells that serve as a template for both developmental and injury-associated retinal angiogenesis. When Lin- HSCs were injected into neonatal mouse eyes, they participated in normal developmental angiogenesis. When EPC-enriched HSCs were injected into the eyes of neonatal $r d / r d$ mice, whose vasculature ordinarily degenerates with age, they prevented the retinal vascular degeneration and this vascular rescue was associated with neuronal rescue [100]. Normal developmental vessels and exogenous progenitor cell targeting to astrocytes and the normal vascular plexus were both found to be dependent on the functional adhesion of R-cadherin as confirmed by disruption of HSCs targeting to the three distinct retinal vascular plexuses following R-cadherin blockade [101].

The role of glial cells during pathological retinal neovascularization is still under investigation. Loss of astrocytes and microglia directly correlates with the development of pathological $\mathrm{NV}$ in a mouse model of oxygen-induced retinopathy (OIR). These two distinct glial cell populations were found to have cooperative survival effects in vitro and in vivo. The intravitreal injection of myeloid progenitor cells, astrocytes, or astrocyteconditioned media rescued endogenous astrocytes from degeneration that normally occurs within the hypoxic, vaso- obliterated retina following return to normoxia. Protection of the retinal astrocytes and microglia was directly correlated with accelerated revascularization of the normal retinal plexuses and reduction of pathological intravitreal neovascularization normally associated with OIR. Using astrocyte-conditioned media, several factors were identified that may contribute to the observed astrocytic protection and subsequent normalization of the retinal vasculature, including vascular endothelial growth factor (VEGF) and basic fibroblast growth factor (bFGF). Injection of VEGF or bFGF at specific doses rescued the retinas from developing OIR-associated pathology, an effect that was also preceded by protection of endogenous glia from hypoxia-induced degeneration. These data suggest that vascular-associated glia are also required for normalized revascularization of the hypoxic retina and protecting glial cells may provide a novel strategy by which normalized revascularization can be promoted and the consequences of abnormal neovascularization in retinal vascular diseases can be prevented [102].

Another condition associated with pathological angiogensis is age related macular degeneration.

Csaky's group demonstrated that EPCs, in the form of OECs can be isolated expanded successfully from the peripheral blood of elderly control and AMD-affected patients and demonstrated significantly higher number of initial OEC clusters and expansion potential of OECs in patients at risk for or already affected by nvAMD. The group postulated that OECs may be used for further phenotypic, genetic, and functional analyses in patients with nvAMD [103].

Proliferative sickle cell retinopathy (PSR) is an uncommon complication in individuals with sickle cell trait, also called AS hemoglobinopathy (HAS), occurring more frequently in patients with SC hemoglobinopathy, S-thalassemia and SS hemoglobinopathy [104]. Interestingly, $\mathrm{KDR}^{+} / \mathrm{CD} 34^{+} /$ $\mathrm{Cd} 45^{\mathrm{dim}}$ cells were found to significantly higher during painful crisis [105], suggesting that patients during sickle crisis may be more at risk for development of ocular neovascularization.

\section{Conclusion}

Even though EPCs constitute a relatively small percentage of circulating cells, they can specifically and effectively home to sites of injury including the retina. Based on the promising results of the REPAIR-AMI trial [106], introduction of non-diabetic EPCs into diabetic patients is being considered to promote wound healing which could guide their use for future treatment of diabetics with extensive retinal or macular ischemia. What exactly is the promise of cellular therapy for diabetic retinopathy? While peripheral blood or bone marrow $\mathrm{CD} 34^{+}$cells show promise, we believe that the ex vivo expanded eEPCs and OECs may 
equally represent cell populations with great therapeutic utility and may provide the basis for an effective cell therapy for vasodegenerative disease in the retina. One population of cells may be responsible for "provisional repair," i.e. transient repair, preparing the environment for more durable repair, which is the function of another EPC population. In healthy retina both populations participate in an ordered, temporal sequence. In NPDR, EPC populations have reduced function as they cannot be recruited into the retina to repair the acellular capillaries, while in PDR the EPCs may take on a pro-inflammatory, proangiogenic phenotype and perhaps too many EPCs lead to pathological neovascularization. While this hypothesis remains to be proven, the concept of identifying the "best" reparative cell and the ideal time for its administration is critically important to the derivation of cellular therapies. In diabetes, dysregulation of $\mathrm{NO}$ is central to phenotypic transitions of these EPC to cells with reduced reparative function and this cellular change may be further influenced by the shifting bone marrow microenvironment associated with diabetes. Ex vivo correction of the diabetesinduced defects in these cells prior to administration to the patient or systemic modulation of the bone marrow to correct the dysfunction of these cells will likely be new strategies for the future to prevent as well as treat diabetic retinopathy.

\section{Future perspective}

The controversy surrounding EPCs will remain an area of active debate and rigorous investigation. The questions remain, what is the source of the vascular reparative cell? Is it the bone marrow or is it the endothelium itself? The field is replete with inconsistencies that have resulted in some disagreement and in differences in terminology used by different groups, such as "endothelial-like cells," instead of endothelial cells, because the precursors express the leukocyte marker CD45. Others justify the outgrowth cells as bona fide products of EPCs based on the observation that the input cells did not express CD45.

It is our feeling that we may be dealing with the same EPCs and that all this disagreement is counterproductive. The EPC may transition through many stages (phases) and may represent the same cell with different phenotypes depending on the isolation conditions or the culture conditions, as it is well established that a little VEGF in the culture medium goes a long way to making the cell appear "endothelial-like" and may explain, in part, the "appearance" of the OEC. Another hurdle is that some investigators find that this "elusive precursor" expresses the hematopoietic marker CD45 while others vehemently argue that it doesn't. The next big question is the therapeutic potential of the EPC. However, since the community can't agree on the actual cell, optimization of its use therapeu- tically will likely be problematic. Careful assessment of the putative cell in vivo will be needed following in vitro characterization.

\section{Key issues}

- It has been a decade since EPCs were discovered but considerable debate remains about the phenotypic nature and cellular derivation of these cells. Defining a correct population of EPC is of salient importance for their therapeutic use.

- Pharmacological manipulation of EPCs will be necessary to correct diabetes associated defects.

- Before clinical use of EPCs, it will be necessary to titrate their dosing regimen to avoid unwanted responses such as accelerated proliferative retinopathy or, perhaps even the initiation of a malignancy.

Acknowledgements This work was supported by grants from the National Institutes of Health (NIH1R01 EY07739, NIH R01EY12601), American Heart Association (Beginning Grant-in-Aid \# 0865213E to S. L. C.) and the Juvenile Diabetes Research Foundation (Grant 4-2000-847).

\section{References}

1. Fong DS, Sharza M, Chen W, et al. Vision loss among diabetics in a group model Health Maintenance Organization (HMO). Am J Ophthalmol. 2002;133:236-41.

2. ETDRS. Early photocoagulation for diabetic retinopathy. ETDRS report number 9. Early Treatment Diabetic Retinopathy Study Research Group. Ophthalmology. 1991;98:766-85.

3. ETDRS. Focal photocoagulation treatment of diabetic macular edema. ETDRS Report Number 19. Arch Ophthalmol. 1995;113:1144-55.

4. Avery RB, Diener-West M, Reynolds SM, et al. Histopathologic characteristics of choroidal melanoma in eyes enucleated after iodine 125 brachytherapy in the collaborative ocular melanoma study. Arch Ophthalmol. 2008;126:207-12.

5. Domen J, Wagers A, Weissman IL. Bone Marrow (hematiopoietic) Stem Cells [Online]. 2006.

6. Yoder MC, Mead LE, Prater D, et al. Redefining endothelial progenitor cells via clonal analysis and hematopoietic stem/ progenitor cell principals. Blood. 2007;109:1801-9.

7. Asahara T, Murohara T, Sullivan A, et al. Isolation of putative progenitor endothelial cells for angiogenesis. Science. 1997;275:964-7.

8. Schatteman GC, Dunnwald M, Jiao C. Biology of bone marrowderived endothelial cell precursors. Am J Physiol Heart Circ Physiol. 2007;292:H1-18.

9. Spring H, Schuler T, Arnold B, et al. Chemokines direct endothelial progenitors into tumor neovessels. Proc Natl Acad Sci U S A. 2005;102:18111-6.

10. Wilson A, Trumpp A. Bone-marrow haematopoietic-stem-cell niches. Nat Rev Immunol. 2006;6:93-106.

11. Rafii S, Lyden D. Therapeutic stem and progenitor cell transplantation for organ vascularization and regeneration. Nat Med. 2003;9:702-12. 
12. Minami E, Laflamme MA, Saffitz JE, et al. Extracardiac progenitor cells repopulate most major cell types in the transplanted human heart. Circulation. 2005;112:2951-8.

13. Ruzinova MB, Schoer RA, Gerald W, et al. Effect of angiogenesis inhibition by Id loss and the contribution of bone-marrow-derived endothelial cells in spontaneous murine tumors. Cancer Cell. 2003;4:277-89.

14. Peters BA, Diaz LA, Polyak K, et al. Contribution of bone marrow-derived endothelial cells to human tumor vasculature. Nat Med. 2005;11:261-2.

15. Caballero S, Sengupta N, Afzal A, et al. Ischemic vascular damage can be repaired by healthy, but not diabetic, endothelial progenitor cells. Diabetes. 2007;56:960-7.

16. Grant MB, May WS, Caballero S, et al. Adult hematopoietic stem cells provide functional hemangioblast activity during retinal neovascularization. Nat Med. 2002;8:607-12.

17. Shi Q, Rafii S, Wu MH, et al. Evidence for circulating bone marrow-derived endothelial cells. Blood. 1998;92:362-7.

18. Fernandez Pujol B, Lucibello FC, Gehling UM, et al. Endothelial-like cells derived from human CD14 positive monocytes. Differentiation. 2000;65:287-300.

19. Eggermann J, Kliche S, Jarmy G, et al. Endothelial progenitor cell culture and differentiation in vitro: a methodological comparison using human umbilical cord blood. Cardiovasc Res. 2003;58:478-86.

20. Delorme B, Basire A, Gentile C, et al. Presence of endothelial progenitor cells, distinct from mature endothelial cells, within human CD146+ blood cells. Thromb Haemost. 2005;94:1270-9.

21. Hur J, Yoon CH, Kim HS, et al. Characterization of two types of endothelial progenitor cells and their different contributions to neovasculogenesis. Arterioscler Thromb Vasc Biol. 2004;24:288-93.

22. Gehling UM, Ergun S, Schumacher U, et al. In vitro differentiation of endothelial cells from AC133-positive progenitor cells. Blood. 2000;95:3106-12.

23. Gulati R, Jevremovic D, Peterson TE, et al. Diverse origin and function of cells with endothelial phenotype obtained from adult human blood. Circ Res. 2003;93:1023-5.

24. Crosby JR, Kaminski WE, Schatteman G, et al. Endothelial cells of hematopoietic origin make a significant contribution to adult blood vessel formation. Circ Res. 2000;87:728-30.

25. Yoon CH, Hur J, Park KW, et al. Synergistic neovascularization by mixed transplantation of early endothelial progenitor cells and late outgrowth endothelial cells: the role of angiogenic cytokines and matrix metalloproteinases. Circulation. 2005;112:1618-27.

26. Kalka C, Masuda H, Takahashi T, et al. Vascular endothelial growth factor(165) gene transfer augments circulating endothelial progenitor cells in human subjects. Circ Res. 2000;86:1198-202.

27. Harraz M, Jiao C, Hanlon HD, et al. CD34- blood-derived human endothelial cell progenitors. Stem Cells. 2001;19:304-12.

28. Rohde E, Malischnik C, Thaler D, et al. Blood monocytes mimic endothelial progenitor cells. Stem Cells. 2006;24:357-67.

29. Schmeisser A, Strasser RH. Phenotypic overlap between hematopoietic cells with suggested angioblastic potential and vascular endothelial cells. J Hematother Stem Cell Res. 2002;11:69-79.

30. Schmeisser A, Garlichs CD, Zhang H, et al. Monocytes coexpress endothelial and macrophagocytic lineage markers and form cord-like structures in Matrigel under angiogenic conditions. Cardiovasc Res. 2001;49:671-80.

31. Romagnani P, Annunziato F, Liotta F, et al. CD14+CD34low cells with stem cell phenotypic and functional features are the major source of circulating endothelial progenitors. Circ Res. 2005;97:314-22.

32. George J, Herz I, Goldstein E, et al. Number and adhesive properties of circulating endothelial progenitor cells in patients with in-stent restenosis. Arterioscler Thromb Vasc Biol. 2003;23:e57-60.
33. Ghani U, Shuaib A, Salam A, et al. Endothelial progenitor cells during cerebrovascular disease. Stroke. 2005;36:151-3.

34. Loomans CJ, Wan $\mathrm{H}$, de Crom $\mathrm{R}$, et al. Angiogenic murine endothelial progenitor cells are derived from a myeloid bone marrow fraction and can be identified by endothelial NO synthase expression. Arterioscler Thromb Vasc Biol. 2006;26:1760-7.

35. Case J, Mead LE, Bessler WK, et al. Human CD34+ AC133+VEGFR-2+ cells are not endothelial progenitor cells but distinct, primitive hematopoietic progenitors. Exp Hematol. 2007;35:1109-18.

36. Loomans CJ, van Haperen R, Duijs JM, et al. Differentiation of bone marrow-derived endothelial progenitor cells is shifted into a proinflammatory phenotype by hyperglycemia. Mol Med. 2009;15:152-9.

37. Donato AJ, Eskurza I, Silver AE, et al. Direct evidence of endothelial oxidative stress with aging in humans: relation to impaired endothelium-dependent dilation and upregulation of nuclear factor-kappaB. Circ Res. 2007;100:1659-66.

38. Imanishi T, Hano T, Sawamura T, et al. Oxidized low-density lipoprotein induces endothelial progenitor cell senescence, leading to cellular dysfunction. Clin Exp Pharmacol Physiol. 2004;31:407-13.

39. Loomans CJ, de Koning EJ, Staal FJ, et al. Endothelial progenitor cell dysfunction: a novel concept in the pathogenesis of vascular complications of type 1 diabetes. Diabetes. 2004;53:195-9.

40. Zhu J, Xu ZK, Miao Y, et al. Changes of inducible protein-10 and regulated upon activation, normal $\mathrm{T}$ cell expressed and secreted protein in acute rejection of pancreas transplantation in rats. World J Gastroenterol. 2006;12:4156-60.

41. Tamarat R, Silvestre JS, Le Ricousse-Roussanne S, et al. Impairment in ischemia-induced neovascularization in diabetes: bone marrow mononuclear cell dysfunction and therapeutic potential of placenta growth factor treatment. Am J Pathol. 2004;164:457-66.

42. Kielczewski JL, Jarajapu YP, McFarland EL, et al. Insulin-like growth factor binding protein-3 mediates vascular repair by enhancing nitric oxide generation. Circ Res. 2009;105:897-905.

43. Ma FX, Zhou B, Chen Z, et al. Oxidized low density lipoprotein impairs endothelial progenitor cells by regulation of endothelial nitric oxide synthase. J Lipid Res. 2006;47:1227-37.

44. Sobrevia L, Mann GE. Dysfunction of the endothelial nitric oxide signalling pathway in diabetes and hyperglycaemia. Exp Physiol. 1997;82:423-52.

45. Weyrich AS, Ma XL, Lefer AM. The role of L-arginine in ameliorating reperfusion injury after myocardial ischemia in the cat. Circulation. 1992;86:279-88.

46. Kaesemeyer WH, Ogonowski AA, Jin L, et al. Endothelial nitric oxide synthase is a site of superoxide synthesis in endothelial cells treated with glyceryl trinitrate. Br J Pharmacol. 2000; 131:1019-23.

47. Berkowitz DE, White R, Li D, et al. Arginase reciprocally regulates nitric oxide synthase activity and contributes to endothelial dysfunction in aging blood vessels. Circulation. 2003;108:2000-6.

48. Jean C, Fromentin G, Tome D, et al. Wistar rats allowed to selfselect macronutrients from weaning to maturity choose a highprotein, high-lipid diet. Physiol Behav. 2002;76:65-73.

49. Ellis EA, Guberski DL, Hutson B, et al. Time course of NADH oxidase, inducible nitric oxide synthase and peroxynitrite in diabetic retinopathy in the BBZ/WOR rat. Nitric Oxide. 2002;6:295304.

50. Camici GG, Schiavoni M, Francia P, et al. Genetic deletion of p66(Shc) adaptor protein prevents hyperglycemia-induced endothelial dysfunction and oxidative stress. Proc Natl Acad Sci U S A. 2007;104:5217-22.

51. Kobayashi T, Taguchi K, Takenouchi Y, et al. Insulin-induced impairment via peroxynitrite production of endotheliumdependent relaxation and sarco/endoplasmic reticulum $\mathrm{Ca}(2+)$ - 
ATPase function in aortas from diabetic rats. Free Radic Biol Med. 2007;43:431-43.

52. Szabo C, Mabley JG, Moeller SM, et al. Part I: pathogenetic role of peroxynitrite in the development of diabetes and diabetic vascular complications: studies with FP15, a novel potent peroxynitrite decomposition catalyst. Mol Med. 2002;8:571- 80 .

53. Munzel T, Sayegh H, Freeman BA, et al. Evidence for enhanced vascular superoxide anion production in nitrate tolerance. A novel mechanism underlying tolerance and cross-tolerance. J Clin Invest. 1995;95:187-94.

54. Bucala R, Tracey KJ, Cerami A. Advanced glycosylation products quench nitric oxide and mediate defective endothelium-dependent vasodilatation in experimental diabetes. J Clin Invest. 1991;87:432-8.

55. Leal EC, Manivannan A, Hosoya K, et al. Inducible nitric oxide synthase isoform is a key mediator of leukostasis and blood-retinal barrier breakdown in diabetic retinopathy. Invest Ophthalmol Vis Sci. 2007;48:5257-65.

56. Stadler K, Bonini MG, Dallas S, et al. Direct evidence of iNOSmediated in vivo free radical production and protein oxidation in acetone-induced ketosis. Am J Physiol Endocrinol Metab. 2008;295:E456-62.

57. Cheng X, Cheng XS, Kuo KH, et al. Inhibition of iNOS augments cardiovascular action of noradrenaline in streptozotocin-induced diabetes. Cardiovasc Res. 2004;64:298-307.

58. Nagareddy PR, Xia Z, McNeill JH, et al. Increased expression of iNOS is associated with endothelial dysfunction and impaired pressor responsiveness in streptozotocininduced diabetes. Am J Physiol Heart Circ Physiol. 2005;289:H2144-52.

59. Aicher A, Zeiher AM, Dimmeler S. Mobilizing endothelial progenitor cells. Hypertension. 2005;45:321-5.

60. Heissig B, Werb Z, Rafii S, et al. Role of c-kit/Kit ligand signaling in regulating vasculogenesis. Thromb Haemost. 2003;90:570-6.

61. Heissig B, Hattori K, Dias S, et al. Recruitment of stem and progenitor cells from the bone marrow niche requires MMP-9 mediated release of kit-ligand. Cell. 2002;109:625-37.

62. Shintani S, Murohara T, Ikeda $\mathrm{H}$, et al. Augmentation of postnatal neovascularization with autologous bone marrow transplantation. Circulation. 2001;103:897-903.

63. Dimmeler S, Fleming I, Fisslthaler B, et al. Activation of nitric oxide synthase in endothelial cells by Akt- dependent phosphorylation. Nature. 1999;399:601-5.

64. Sorrentino SA, Bahlmann FH, Besler C, et al. Oxidant stress impairs in vivo reendothelialization capacity of endothelial progenitor cells from patients with type 2 diabetes mellitus: restoration by the peroxisome proliferator-activated receptorgamma agonist rosiglitazone. Circulation. 2007;116:163-73.

65. Thum T, Fraccarollo D, Schultheiss M, et al. Endothelial nitric oxide synthase uncoupling impairs endothelial progenitor cell mobilization and function in diabetes. Diabetes. 2007; 56:666-74.

66. Vasa M, Breitschopf K, Zeiher AM, et al. Nitric oxide activates telomerase and delays endothelial cell senescence. Circ Res. 2000;87:540-2.

67. Li Calzi S, Purich DL, Hee Chang K, et al. Carbon monoxide and nitric oxide mediate cytoskeletal reorganization in microvascular cells via Vasodilator-Stimulated Phosphoprotein (VASP) phosphorylation: evidence for blunted responsiveness in diabetes. Diabetes. 2008.

68. Segal MS, Shah R, Afzal A, et al. Nitric oxide cytoskeletal-induced alterations reverse the endothelial progenitor cell migratory defect associated with diabetes. Diabetes. 2006;55:102-9.

69. Grunewald M, Avraham I, Dor Y, et al. VEGF-induced adult neovascularization: recruitment, retention, and role of accessory cells. Cell. 2006;124:175-89.
70. Jarajapu YP, Thampi P, Caballero S, et al. Differential Paracrine Dysfunction and Hypoxic Desensitization in Diabetic CD34+ and CD14+ Bone Marrow Derived Cells (BMDC). Circulation. 2009;120:S1124.

71. Gao J, Zhao WX, Zhou LJ, et al. Protective effects of propofol on lipopolysaccharide-activated endothelial cell barrier dysfunction. Inflamm Res. 2006;55:385-92.

72. Luo T, Xia Z, Ansley DM, et al. Propofol dose-dependently reduces tumor necrosis factor-alpha-Induced human umbilical vein endothelial cell apoptosis: effects on Bcl-2 and Bax expression and nitric oxide generation. Anesth Analg. 2005;100:1653-9.

73. Chen YS, Chen KH, Liu CC, et al. Propofol-induced vascular permeability change is related to the nitric oxide signaling pathway and occludin phosphorylation. J Biomed Sci. 2007;14:629-36.

74. Dimmeler S, Aicher A, Vasa M, et al. HMG-CoA reductase inhibitors (statins) increase endothelial progenitor cells via the PI 3-kinase/Akt pathway. J Clin Invest. 2001;108:391-7.

75. Landmesser U, Engberding N, Bahlmann FH, et al. Statininduced improvement of endothelial progenitor cell mobilization, myocardial neovascularization, left ventricular function, and survival after experimental myocardial infarction requires endothelial nitric oxide synthase. Circulation. 2004;110:1933-9.

76. Verma S, Szmitko PE, Anderson TJ. Endothelial function: ready for prime time? Can J Cardiol. 2004;20:1335-9.

77. Thum T, Fraccarollo D, Galuppo P, et al. Bone marrow molecular alterations after myocardial infarction: Impact on endothelial progenitor cells. Cardiovasc Res. 2006;70:50-60.

78. Achan V, Broadhead M, Malaki M, et al. Asymmetric dimethylarginine causes hypertension and cardiac dysfunction in humans and is actively metabolized by dimethylarginine dimethylaminohydrolase. Arterioscler Thromb Vasc Biol. 2003;23:1455-9.

79. Dayoub H, Achan V, Adimoolam S, et al. Dimethylarginine dimethylaminohydrolase regulates nitric oxide synthesis: genetic and physiological evidence. Circulation. 2003;108:3042-7.

80. Busik J, Tikhonenko M, Bhatwadekar A, et al. Diabetic retinopahty is associated with bone marrow neuropathy and a depressed peripheral clock. J Exp Med. Epub ahead of time. 2009.

81. Naveiras O, Nardi V, Wenzel PL, et al. Bone-marrow adipocytes as negative regulators of the haematopoietic microenvironment. Nature. 2009.

82. Berria R, Glass L, Mahankali A, et al. Reduction in hematocrit and hemoglobin following pioglitazone treatment is not hemodilutional in type II diabetes mellitus. Clin Pharmacol Ther. 2007;82:275-81.

83. Digman C, Borto D, Nasraway Jr SA. Hyperglycemia in the critically ill. Nutr Clin Care. 2005;8:93-101.

84. Maaravi Y, Stessman J. Mild, reversible pancytopenia induced by rosiglitazone. Diabetes Care. 2005;28:1536.

85. Lazarenko OP, Rzonca SO, Hogue WR, et al. Rosiglitazone induces decreases in bone mass and strength that are reminiscent of aged bone. Endocrinology. 2007;148:2669-80.

86. Corre J, Barreau C, Cousin B, et al. Human subcutaneous adipose cells support complete differentiation but not self-renewal of hematopoietic progenitors. J Cell Physiol. 2006;208:282-8.

87. Nishikawa S, Kumar PK, Jeoung YH, et al. Chemical probing studies of the hepatitis delta virus (HDV) genomic ribozyme. Nucleic Acids Symp Ser. 1993:119-20.

88. Belaid-Choucair Z, Lepelletier Y, Poncin G, et al. Human bone marrow adipocytes block granulopoiesis through neuropilin-1induced granulocyte colony-stimulating factor inhibition. Stem Cells. 2008;26:1556-64.

89. Miharada K, Hiroyama T, Sudo K, et al. Lipocalin 2-mediated growth suppression is evident in human erythroid and monocyte/ macrophage lineage cells. J Cell Physiol. 2008;215:526-37.

90. Yan QW, Yang Q, Mody N, et al. The adipokine lipocalin 2 is regulated by obesity and promotes insulin resistance. Diabetes. 2007;56:2533-40. 
91. Yokota T, Oritani K, Takahashi I, et al. Adiponectin, a new member of the family of soluble defense collagens, negatively regulates the growth of myelomonocytic progenitors and the functions of macrophages. Blood. 2000;96:1723-32.

92. Zhang Y, Harada A, Bluethmann H, et al. Tumor necrosis factor (TNF) is a physiologic regulator of hematopoietic progenitor cells: increase of early hematopoietic progenitor cells in TNF receptor p55deficient mice in vivo and potent inhibition of progenitor cell proliferation by TNF alpha in vitro. Blood. 1995; 86:2930-7.

93. DiMascio L, Voermans C, Uqoezwa M, et al. Identification of adiponectin as a novel hemopoietic stem cell growth factor. J Immunol. 2007;178:3511-20.

94. Awad O, Jiao C, Ma N, et al. Obese diabetic mouse environment differentially affects primitive and monocytic endothelial cell progenitors. Stem Cells. 2005;23:575-83.

95. Klein R, Knudtson MD, Lee KE, et al. The Wisconsin Epidemiologic Study of Diabetic Retinopathy: XXII the twenty-five-year progression of retinopathy in persons with type 1 diabetes. Ophthalmology. 2008;115:1859-68.

96. Fadini GP, Miorin M, Facco M, et al. Circulating endothelial progenitor cells are reduced in peripheral vascular complications of type 2 diabetes mellitus. J Am Coll Cardiol. 2005;45:1449-57.

97. Kusuyama T, Omura T, Nishiya D, et al. Effects of treatment for diabetes mellitus on circulating vascular progenitor cells. J Pharmacol Sci. 2006;102:96-102.

98. Lee IG, Chae SL, Kim JC. Involvement of circulating endothelial progenitor cells and vasculogenic factors in the pathogenesis of diabetic retinopathy. Eye (Lond). 2006;20:546-52.
99. Brunner S, Schernthaner GH, Satler M, et al. Correlation of different circulating endothelial progenitor cells to stages of diabetic retinopathy: first in vivo data. Invest Ophthalmol Vis Sci. 2009;50:392-8.

100. Otani A, Kinder K, Ewalt K, et al. Bone marrow-derived stem cells target retinal astrocytes and can promote or inhibit retinal angiogenesis. Nat Med. 2002;8:1004-10.

101. Dorrell MI, Otani A, Aguilar E, et al. Adult bone marrow-derived stem cells use R-cadherin to target sites of neovascularization in the developing retina. Blood. 2004;103:3420-7.

102. Dorrell MI, Friedlander M. Mechanisms of endothelial cell guidance and vascular patterning in the developing mouse retina. Prog Retin Eye Res. 2006;25:277-95.

103. Thill M, Strunnikova NV, Berna MJ, et al. Late outgrowth endothelial progenitor cells in patients with age-related macular degeneration. Invest Ophthalmol Vis Sci. 2008;49:2696-708.

104. Livrea MA, Tesoriere L, Pintaudi AM, et al. Oxidative stress and antioxidant status in beta-thalassemia major: iron overload and depletion of lipid-soluble antioxidants. Blood. 1996;88:3608-14.

105. van Beem RT, Nur E, Zwaginga JJ, et al. Elevated endothelial progenitor cells during painful sickle cell crisis. Exp Hematol. 2009;37:1054-9.

106. Schachinger V, Erbs S, Elsasser A, et al. Improved clinical outcome after intracoronary administration of bone-marrow-derived progenitor cells in acute myocardial infarction: final 1-year results of the REPAIR-AMI trial. Eur Heart J. 2006;27:2775-83. 